\title{
The Effect of Ginger Capsule on Nausea and Vomiting during and after Caesarean Section under Spinal Anesthesia
}

\author{
Mahbobeh Amouee ${ }^{*}$, Simin Montazeri², Reza Akhond Zadeh1', Maryam Ghorbani ${ }^{3}$ \\ ${ }^{1}$ Jondi Shapour University of Medical Sciences, Ahvaz, Iran \\ ${ }^{2}$ Department of Midwifery, Jondi Shapour University of Medical Sciences, Ahvaz, Iran \\ ${ }^{3}$ Shahid Beheshti University of Medical Sciences, Tehran, Iran \\ Email: "n57_m57@yahoo.com
}

Received 7 October 2015; accepted 26 January 2016; published 29 January 2016

Copyright @ 2016 by authors and Scientific Research Publishing Inc.

This work is licensed under the Creative Commons Attribution International License (CC BY). http://creativecommons.org/licenses/by/4.0/

(c) (i) Open Access

\section{Abstract}

Objective: To study the efficacy of ginger on the Nausea and Vomiting during and after Cesarean Section under Spinal Anesthesia. Study Design: Double blind randomized controlled trial. Setting: Department of Obstetrics and Gynecology, Ahvaz University, Razi Hospital. Material and Method: From January 2008 to April 2008, 70 pregnant women underwent for elective cesarean section under spinal anesthesia were randomized received coded drug one hour prior section with $30 \mathrm{ml}$ water. The patients were at term, single pregnancy, uterine and abdominal incision transversal, and spinal anesthesia with lidocain $5 \%$. Patients were matched in two groups by these factors: age, height, weight, BMI, cause of cesarean section, gestational age, hypotention during and after cesarean section, duration of operation and nausea and vomiting in pregnancy. All patients were assessed for severity of nausea by visual analog nausea score (VANS). Frequency of vomiting and need antiemetic drug were evaluated during and $0 / 5,1,2,4,6$ hours after cesarean section. Results: The results demonstrated the statistically significant differences in severity of nausea and vomiting during cesarean section $(p=0 / 000)$. Severity of nausea $(p=0 / 000)$ and vomiting $(0 / 046)$ after cesarean section also was lower in ginger group than placebo group. There were statistically significant differences between two groups for need antiemetic drug during $(0 / 000)$ and after $(0 / 003)$ cesarean section. This need was lower in ginger group than placebo group. Side effects caused by ginger were not detected. Conclusion: Ginger has efficacy in decrease severity of nausea and vomiting during and after cesarean section under spinal anesthesia.

\section{Keywords}

Ginger, Cesarean Section, Regional Anesthesia, Nausea, Vomiting

\footnotetext{
"Corresponding author.
} 


\section{Introduction}

More than 23 million surgical procedures are performed annually [1]. As a major surgical procedure, caesarean section is the most common surgery in most hospitals in the Unites States [2], where it has quadrupled in the last two decades [3]. There are some complications related to cesarean section, among which the complications of anesthesia cause seven percent of maternal mortality [4]. In recent years, spinal anesthesia is used more than general anesthesia [5]. Spinal anesthesia is the most common anesthesia method for elective cesarean section [6], but it also has some complications such as decreased blood pressure, spinal headaches, itching, nausea and vomiting. The latter complication occurs in $46 \%-80 \%$ of cesarean section under spinal anesthesia [7]. Pan (1992) and Balki et al. (2005) reported the prevalence of nausea and vomiting during surgery more than 66\% [8] and $80 \%$ of cases, respectively [9]. Despite dramatic advances in anesthesia techniques, the prevalence of nausea and vomiting has also remained constant in the past 30 years [10]. Pregnant women undergoing spinal anesthesia are more prone to nausea and vomiting during surgery due to orthostatic hypotension and progesterone-dependent relaxation of smooth muscles and decreased gastrointestinal motility and esophageal sphincter tone [9]. In the United States, the average treatment cost for a patient experiencing nausea and vomiting after cesarean section is 14.94 dollars including personnel wages, supplements, medications, increased hospital stay in post-op care unit, and amounts to about 253,000 - 520,000 dollars in a fiscal year [11]. Postoperative nausea and vomiting can cause dehydration, electrolyte disorders, increased blood pressure, tension on suture lines and bleeding from the subcutaneous tissue [12]. Persistent vomiting can delay discharge from the recovery room for 47 - 60 minutes [13]. Aspiration of gastric contents and undigested foods blocks airways and eventually leads to pneumonia, atelectasis and death [14]. Several studies have evaluated the therapeutic effect of different medications and techniques on nausea and vomiting during and after surgery, including anticholinergics, antihistamines, and serotonin antagonists [12] [15]; but each of these medications have complications such as long recovery time, restlessness, anxiety, dry mouth, increased dizziness after surgery, and increased blood pressure [5] [12] [16]. Many physicians tend to use complementary treatments because of the complications of these medications, the cost of new medications and their incomplete success [17] [18]. Some studies report using nonpharmacological methods such as acupuncture, acupressure, music therapy and herbal therapy [18]-[20]. Ginger root is a common old spice, recognized as a dietary supplement by the Food and Drug Administration (FDA) [21] and without any complications or interaction with other medications as mentioned in Commission E monograph [22].

Granger writes that galanolactone antagonists, 5-hydroxytryptamine-3 receptors and serotonin-3 in ginger may explain antiemetic properties and increased gastrointestinal motility [20]. Gingerol and shogaol in ginger inhibit stomach contractions, increase gastrointestinal motility, stimulate bowel peristalsis and eliminate free radicals that stimulate vomiting [23].

This study was conducted considering the importance of controlling nausea during and after cesarean section because of the mentioned risks and establishing an immediate emotional bond between mother and baby and initiating breastfeeding.

\section{Materials and Methods}

This study was a double-blind clinical trial conducted in Razi Hospital, Ahvaz (Iran). Of the pregnant women presenting to the hospital for elective cesarean delivery, 70 qualified women with a history of one to three pregnancies, aged between 18 and 35 years and the full-term gestational age were selected (94 women were entered into the research according to Cochran formula and finally 70 women were selected). Pregnant women did not have any gastrointestinal diseases, motion sickness, nausea and vomiting in previous anesthesia experiences, morbid obesity and a history of hyperemesis gravidarum, a history of nausea and vomiting during the 24 hours before surgery, underlying diseases or complications of pregnancy such as pregnancy hypertension. Before surgery, patients received similar training about the use of visual analog scale for nausea and one hour before surgery, the subjects received coded capsules with 30 cc of water. Ginger capsules were manufactured by Goldaru Company and each capsule contained $250 \mathrm{mg}$ of ginger root powder approved by a pharmacognosy expert and placebo capsules contained rice flour. These patients did not receive any medication before surgery.

Patients were hydrated with 500 cc of Ringer's solution in the operating room, and then an anesthetist performed spinal anesthesia with the injection of 50 - $100 \mathrm{mg}$ lidocaine (5\%) in L3-4 or L4-5 space using 24 - 25 gaugeneedle. If systolic blood pressure dropped more than $20 \%$ as compared with the initial pressure or less 
than $100 \mathrm{mmHg}$, routine treatments were performed including glowering the head of the bed, increasing Ringer's solution infusion rate or injecting 5 - $10 \mathrm{mg}$ intravenous ephedrine. Patients' blood pressure was monitored every minute until it became normal and all women received 5 liters per minute of oxygen until the birth. After the birth of the baby, 40 units of syntocinon was intravenously infused. After the surgery, women were transferred to the recovery room and then to the gynecology ward after their foot sensation was restored and their vital signs and complications were stabilized. The researcher recorded women's nausea and vomiting status and antiemetic medications received during surgery and 0.5, 1, 2, 6, 4 hours after the end of surgery.

Visual analog scale, a 100-mm line with specific beginning, end and range, was used to assess nausea severity, as patients marked their status on it from zero to represent the best situation and the absence of the target complication to 100 to represent the worst situation. This scale was used in several studies on quality of life and its reliability was determined from $40 \%$ to $95 \%$ [5]. Visual analog scale for nausea severity is a self-report scale. Since nausea is felt by the patient, self-report scale is an appropriate technique to measure its severity. In addition, it can be easily understood by the subject and its usage can be taught simply [24]. Nausea is classified as mild, moderate and severe if it scores, respectively, less than 3.5, between 3.5 and 7, and greater than 7 [25].

The number of retching or vomiting was also used to assess nausea severity, which was rated severe, moderate and severe if retching or vomiting occurred more than 5 times, between 3 and 5 times and fewer than 3 times, respectively [26].

If patients could tolerate nausea, they did not receive any medication, but in case nausea was intolerable, or retching or vomiting occurred, they received $10 \mathrm{mg}$ metoclopramide. It should be noted that all women were transferred in a similar way to the gynecology ward on a stretcher in order to remove the effects of patients' movement on nausea and vomiting. Patients received $2 \mathrm{~g}$ of cefazolin simultaneous with baby's shoulder delivery and postoperative antibiotics was $1 \mathrm{~g}$ IV infusion of cefazolin as according to the gynecology ward routine. The data obtained were analyzed in SPSS-15 software using t-test, chi-square, and descriptive statistics to determine the frequency and the percentage of data obtained. The significance level was set as $\mathrm{p}<0.05$.

\section{Results}

Data from the two study groups, including age, weight, height, BMI, gestational age, duration of surgery, duration of preoperative fasting, the ephedrine used during and after surgery using t-test are presented in Table 1. The mean duration of surgery was $45.8 \mathrm{~min}$ in the trial group and $46.2 \mathrm{~min}$ in the control group, with no significant difference between the two groups as confirmed by t-test $(p=0.368)$ (Table 1$)$.

The highest frequency of nausea severity during surgery was moderate nausea of 11 women $(31.4 \%)$ in the trial group and severe nausea of 18 women (51.4\%) in the control. The difference in nausea severity experienced during surgery was reported significant between the two groups by t-test $(\mathrm{p}=0.0001)$ (Table 2).

Seven women (20\%) in the trial group and 22 women (62.9\%) in the control group vomited during surgery and the Chi-square test reported a significant difference between the two groups in this regard $(p=0.0001)$.

The following results were obtained on the severity of vomiting during surgery: the most frequent vomiting severity during surgery was mild vomiting of six women (17.1\%) in the trial group, but moderate vomiting of 11 women (31.4\%) in the control group. The difference in the mean frequency of vomiting between the two groups was reported significant by t-test $(\mathrm{p}=0.0001)$ (Table 3$)$.

The need for metoclopramide during surgery was reported significant by the chi-square test between the groups ( $\mathrm{p}=0.0001)$. The amount was $22.9 \%(\mathrm{n}=8)$ in the ginger group and $77.1 \%(\mathrm{n}=27)$ in the placebo group.

The results on the control of nausea 6 hours after surgery showed that the overall distribution of nausea between the two groups in different hours after surgery was not statistically significant by the Mantel-Haenszel chi-square test $(p=0.07)$. Repeated-measures analysis of variance showed that the mean severity of postoperative nausea was significantly different between the two groups $(\mathrm{p}=0.0001)$, and the difference was significant by t-test in half an hour ( $\mathrm{p}=0.0001)$ and one hour $(\mathrm{p}=0.02)$ after surgery (Table 2$)$.

The following results were obtained on the control of vomiting 6 hours after surgery: the overall distribution of vomiting between the two groups in different hours after surgery was statistically significant by the MantelHaenszel chi-square test $(p=0.026)$. Repeated-measures analysis of variance showed that the mean severity of postoperative vomiting was statistically significant between the two groups $(p=0.046)$, and the difference was significant by t-test in half an hour after surgery $(\mathrm{p}=0.02)$ (Table 3$)$. None of the women vomited four and six hours after surgery. 
Table 1. Comparison of demographic variables and information related to ginger and control groups in terms of mean and standard deviation using t-test.

\begin{tabular}{cccc}
\hline Variables & $\begin{array}{c}\text { Ginger group }(\mathrm{n}=35) \\
(\text { mean } \pm \text { SD) }\end{array}$ & $\begin{array}{c}\text { Control group }(\mathrm{n}=35) \\
(\text { mean } \pm \text { SD) }\end{array}$ & p value \\
\hline Age (year) & $25 \pm 3.6$ & $24.8 \pm 3.4$ & 0.775 \\
Weight (kg) & $79.1 \pm 11.6$ & $74 \pm 10.7$ & 0.061 \\
Height (cm) & $164.9 \pm 6.1$ & $164.9 \pm 6.1$ & 0.969 \\
BMI (kg/m $\left.{ }^{2}\right)$ & $29 \pm 4.1$ & $24.7 \pm 3.4$ & 0.075 \\
Gestational age (week) & $39 \pm 0.5$ & $39.2 \pm 0.5$ & 0.105 \\
Duration of surgery (min) & $45.8 \pm 5$ & $46.2 \pm 5.2$ & 0.773 \\
Ephedrine used during surgery (mg) & $13 \pm 8.7$ & $14.1 \pm 7.1$ & 0.551 \\
Ephedrine used after surgery (mg) & $2.8 \pm 1.4$ & $2.9 \pm 1.8$ & 0.542 \\
Duration of fasting & $8.6 \pm 0.4$ & $8.5 \pm 0.4$ & 0.296 \\
\hline
\end{tabular}

Table 2. Comparison of nausea severity during and after caesarean section under spinal anesthesia in subjects.

\begin{tabular}{|c|c|c|c|}
\hline Variables & $\begin{array}{l}\text { Ginger group }(\mathrm{n}=35) \\
\quad(\text { mean } \pm \mathrm{SD})\end{array}$ & $\begin{array}{l}\text { Control group }(\mathrm{n}=35) \\
\quad(\text { mean } \pm \text { SD })\end{array}$ & $\mathrm{p}$ value \\
\hline Nausea severity during surgery & $2.8 \pm 2.8$ & $6.3 \pm 3.4$ & 0.000 \\
\hline Nausea severity half an hour after surgery & $1.3 \pm 0.6$ & $3.1 \pm 3$ & 0.000 \\
\hline Nausea severity 0.5 - 1 hour after surgery & $1.1 \pm 0.5$ & $1.8 \pm 1.3$ & 0.27 \\
\hline Nausea severity 1 - 2 hour after surgery & $1.2 \pm 0.4$ & $1.6 \pm 0.58$ & 0.261 \\
\hline Nausea severity 2 - 4 hour after surgery & $0.7 \pm 0.2$ & $0.8 \pm 0.2$ & 0.882 \\
\hline Nausea severity 4 - 6 hour after surgery & $1.6 \pm 0.03$ & - & 0.321 \\
\hline
\end{tabular}

Table 3. Comparison of vomiting severity during and after caesarean section under spinal anesthesia in subjects.

\begin{tabular}{cccc}
\hline Variables & $\begin{array}{c}\text { Ginger group }(\mathrm{n}=35) \\
(\text { mean } \pm \text { SD) }\end{array}$ & $\begin{array}{c}\text { Control group }(\mathrm{n}=35) \\
(\text { mean } \pm \text { SD) }\end{array}$ & p value \\
\hline Vomiting severity during surgery & $1 \pm 0.5$ & $2.7 \pm 2.7$ & 0.000 \\
Vomiting severity half an hour after surgery & $0.6 \pm 0.3$ & $0.3 \pm 0.06$ & 0.321 \\
Vomiting severity 0.5 - 1 hour after surgery & - & $0.3 \pm 0.06$ & 0.321 \\
Vomiting severity $1-2$ hour after surgery & - & - & - \\
Vomiting severity $2-4$ hour after surgery & - & - & - \\
Vomiting severity $4-6$ hour after surgery & - & & -
\end{tabular}

The need for anti-emetic medication after surgery was reported significant by the chi-square test. Ten women (28.6\%) in the control group versus 2 women $(5.7 \%)$ in the test group needed metoclopramide $(p=0.011)$.

\section{Discussion}

This study aimed to evaluate the effect of ginger capsule on nausea and vomiting during and after caesarean section under spinal anesthesia. There is a high prevalence of nausea and vomiting during and after caesarean section, and although metoclopramide is the most common medication used to control or prevent this complication; 
its occasional extrapyramidal complications are always a concern for its administration [27]. Various factors affect nausea and vomiting during and after cesarean section, such as age, education, anxiety, weight, height, and BMI, but we did not find a significant difference between the two groups regard these variables.

Since reduced blood pressure can cause ischemia of the brain stem and stimulate vomiting center in the brain stem and also hypotension during and after surgery can lead to bowel ischemia and release of nausea-causing substances such as serotonin [27], this variable was studied in the two groups and there was no difference in two groups in this regard.

As the results showed, ginger led to a decrease in the incidence and severity of nausea and vomiting during and after cesarean section and also the need for anti-emetic medication.

The incidence of nausea during surgery in the placebo group was 80\%, Pan (1992) reported the prevalence of nausea during cesarean section 66\% [8] and Balki et al. (2005) reported the prevalence in the cesarean section under spinal anesthesia $80 \%$ [9].

Tongta et al. (2006) concluded that ginger reduced nausea and vomiting after surgery. It also reduced the need for anti-emetic medication which is roughly consistent with the present study. Tongta also concluded that the mean severity of postoperative nausea in the hours he investigated (immediately, two and six hours after surgery) was less in the ginger group than in the placebo group. But nausea severity two and six hours after surgery was statistically significant [29].

In the present study, mean severity of postoperative nausea in the hours investigated (half, one, two and four hours after surgery) was less in the ginger group than in the placebo group. But it was statistically significant half and one hour after surgery. It seems that this significant difference in the hours after surgery is due to the type of anesthesia, type of surgery, and duration of surgery. In his study, the type of anesthesia was general anesthesia and the type of surgery was hysterectomy and other gynecology procedures and the average duration of surgery was 127.08 minutes.

Sirrirat et al. (2006) also concluded that ginger is effective in preventing postoperative nausea in gynecology surgeries and in preventing postoperative vomiting is nearly significant. In their study, the mean severity of postoperative nausea two and six hours after surgery was less in the ginger group than in the placebo group. But it was statistically significant six hours after surgery [30].

Phillips et al. (1992) in their study to determine the effect of ginger with metoclopramide in reducing nausea and vomiting after gynecology surgeries in 120 patients concluded that the antiemetic effect of ginger was significant compared to placebo and also the incidence of postoperative nausea and vomiting was $21 \%$, 27\% and $41 \%$ in the ginger group, the metoclopramide group and the placebo group respectively. Phillips concluded that the effect of one gram of ginger is equivalent to $10 \mathrm{mg}$ metoclopramide [31].

Grainger writes that galanolactone antagonists, 5-hydroxytryptamine-3 receptors and serotonin-3 in ginger may explainits antiemetic properties and increased gastrointestinal motility [32].

Bone et al. (1990) compared the antiemetic effect of ginger with placebo and metoclopramide on postoperative nausea and vomiting and found that the postoperative nausea and vomiting was less in patients who received ginger or metoclopramide compared to patients who received placebo. The frequency of vomiting in groups that had received ginger or metoclopramide was less than that in the placebo group. The need for metoclopramide was also reduced in patients [33]. The results of this study are consistent with the present study.

Nonetheless, Visalyputra (1998) suggested that ginger powder at a dose of $2 \mathrm{~g}$ and droperidol at a dose of $1.25 \mathrm{mg}$, or both were ineffective in reducing nausea and vomiting after laparoscopy [34]. Arfeen (1995) and Leopold (2003) also found negative results in their studies [35] [36] maybe due to the fact that the number of patient evaluations was low by these researchers. Visalyputra evaluated patients once after surgery and once at the time of discharge and Leopold used very low doses of ginger (300 and $600 \mathrm{mg}$ ).

Given that $93 \%$ of anesthetists believe nausea and vomiting are intractable [5] and in this study ginger capsule could decrease nausea severity to some extent during and after caesarean section under spinal anesthesia, it can be used as a useful medication by anesthesiologists and all personnel performing care during and after cesarean section as the most common surgery.

\section{Conclusion}

Ginger has efficacy in decrease severity of nausea and vomiting during and after cesarean section under spinal anesthesia. 


\section{Acknowledgements}

This research is derived from the master thesis in the nursing and midwifery department of Ahvaz Medical University. We appreciate the cooperation by honorable research deputy of university and all participants in this study.

\section{References}

[1] Gottschalk, A. and Smith, D.S. (2001) New Concept in Acute Pain Therapy. Peemptive Analgesia, 63, $1979-1984$.

[2] Yahyavi, S.H. and Nazari, L. (2006) Role of Haloperidol in Managing Gynecologic-Related Postoperative Nausea and Vomiting. Medical Sciences Journal of Islamic Azad University, 15, 9-14.

[3] Guningham, G. and Norman, F. (2005) Wiliams Obstetrics. 22nd Edition, McGraw-Hill, 537-566.

[4] Humminki, E. and Mriliang, G. (1996) Long Term Effect of Cesarean Section; Ectopic Pregnancy and Placenta Previa. American Journal of Obstetrics \& Gynecology, 174, 1569-1574. http://dx.doi.org/10.1016/S0002-9378(96)70608-7

[5] Montazeri, S., Poor Mehdi, Z., Latifi, S.M. and Aghaei, M. (2001) Evaluation Acupressure Effect on Nausea and Vomiting during and after Cesarean Section under Spinal Anesthesia in Pregnant Women Referred to Razi Hospital. Ahvaz of Med Scien J, 4, 9-15.

[6] Naylor, R.J. and Inall, F.C. (1994) The Physiology and Pharmacology of Postoperative Nausea and Vomiting. Anesthesia, 49, 2-5. http://dx.doi.org/10.1111/j.1365-2044.1994.tb03575.x

[7] Stein, D.J., et al. (1997) Acupressure versus Intravenous Metoclopramid to Prevent Nausea and Vomiting during Spainal Anesthesia for Cesarean Section. Anesthesia \& Analgesia, 84, 342.

[8] Pan, P.H. and Moor, C.H. (1992) Intraoperative Antiemetic Efficacy of Profilactic on Dansetron versus Droperidol for Cesarean Section Patient under Epidural Anesthesia. Anesthesia \& Analgesia, 83, 982-986.

[9] Balki, J. and Carvalho, A. (2005) Intraoperative Nausea and Vomiting during Cesarean Section under Regional Anesthesia. International Journal of Obstetric Anesthesia, 14, 230-241. http://dx.doi.org/10.1016/j.ijoa.2004.12.004

[10] Toner, C.C., Bromhead, C.J. and John, I.H. (1996) Prediction of Postoperative Nausea and Vomiting Using a Logistic Regression Model. British Journal of Anaesthesia, 76, 347-351. http://dx.doi.org/10.1093/bja/76.3.347

[11] Thompson, H.J. (1992) The Management of Postoperative Nausea and Vomiting. Journal of Advanced Nursing, 22, 11130-11136.

[12] Hosseini Jahromi, S.A., Hosseini Valami, S.M. and Tabrizi Jam, N. (2004) Use of Betamethasone in Prevention of Postoperative Pain, Nausea and Vomiting. Yazd of Med Scien J, 10, 43-48.

[13] Caroline, S.A. (2004) Randomized Controlled Trial of Ginger to Treat Nausea and Vomiting in Pregnancy. Obstetrics \& Gynecology, 103, 639-645. http://dx.doi.org/10.1097/01.AOG.0000118307.19798.ec

[14] Cuningham, F.G. and Norman, F. (2001) Wiliams Obstetrics. 21st Edition, McGraw-Hill, New York, 537-566.

[15] Kenny, G.N. (1994) Risk Factors for Postoperative Nausea and Vomiting. Anesthesia, 49, 6-10. http://dx.doi.org/10.1111/j.1365-2044.1994.tb03576.x

[16] Heidari, S.M., Kashefi, P., Rahimi, M. and Eskandari, M. (2007) The Effect of Different Concentrations of Oxygen on Postoperative Nausea and Vomiting after Spinal Anesthesia. Journal of Shahrekord University of Medical Sciences, 8, 9-15.

[17] Anoyamous, R. (2000) Nausea and Vomiting in Early Pregnancy. Bandolier, 59-64.

[18] Myrna, E., Mamaril, M.S. and Pamela, E. (2006) Prevention and Management of Postoperative Nausea and Vomiting: A Look at Complementary Techniques. Journal of PeriAnesthesia Nursing, 21, 404-410. http://dx.doi.org/10.1016/j.jopan.2006.09.007

[19] Fazel, N. (2003) The Effect of Supermint Oil on Pain Severity after Cesarean Section. Journal of Babol University of Medical Sciences, 7, 28-33.

[20] Vilming, B. and Nesheim, B. (2000) Hyperemesis Gravidarum in a Contemporary Population in Olso. Acta Obstetricia et Gynecologica Scandinavica, 79, 640-643.

[21] Ozgoli, G., Goli, M., Moattar, F. and Valaie, N. (2007) Comparing Ginger with Mefenamic Acid and Ibubrofen for the Treatment of Primary Dysmenorrheal. Pajohesh of Med J, 31, 61-65.

[22] Blumental, M. (1998) The Complete German Commission E Monographs. American Botanical Council, Austin, 136.

[23] Manusirivithaya, M., Sripramote, S. and Tangjitamol, C. (2004) Antiemetic Effect of Ginger in Gynecologic Oncology Patients Receiving Cisplatin. International Journal of Gynecological Cancer, 14, 1063-1069. http://dx.doi.org/10.1111/j.1048-891X.2004.14603.x 
[24] Rhodes, V.A. and Watson, P.M. (1984) Development or Reliable and Valid Measures of Nausea and Vomiting. Cancer Nursing, 7, 33-34. http://dx.doi.org/10.1097/00002820-198402000-00003

[25] Kortilla, K. (1992) The Study of Postoperative Nausea and Vomiting. British Journal of Anesthesia, 69, 205-235. http://dx.doi.org/10.1093/bja/69.supplement_1.20S

[26] Harmon, D., Gardiner, J. and Harrison, R. (1999) Acupressure and the Prevention of Nausea and Vomiting after Laparoscopy. British Journal of Anesthesia, 82, 387-390. http://dx.doi.org/10.1093/bja/82.3.387

[27] Pazoki, S., Eskandari, M., Memari, S., Norouzi, A. and Zarganj-Fard, A. (2007) The Effectiveness of Metoclopramide, Dexamethasone and Propofol in Controlling Intraoperative Nausea and Vomiting during Spinal Anesthesia for Emergency Cesarean Section. Journal of Arak University of Medical Sciences, 9, 1-6.

[28] Huang, Q., Wamoto, I. and Aoki, M. (1991) Anti 5-Hydroxytryptamine Effect of Galanolactone, Diterpenoid Isolated from Ginger. Chemical and Pharmaceutical Bulletin, 39, 397-399. http://dx.doi.org/10.1248/cpb.39.397

[29] Tongta, N. and Densak, P. (2006) The Efficacy of Ginger in Prevention of Postoperative Nausea and Vomiting after Major Gynecologic Surgery. Journal of the Medical Association of Thailand, 89, 130-136.

[30] Sirrirat, A., Sawinee, R. and Budsaba, W. (2006) Effectiveness of Ginger for Prevention of Nausea and Vomiting after Gynecological Laparascopy. Journal of the Medical Association of Thailand, 89, 2003-2009.

[31] Phillips, S., Ruggier, R. and Hutchinso, S.E. (1993) Zingiber officinale (Ginger)—An Antiemetic for Day Case Surgery. Journal of Anesthesia, 48, 715-717.

[32] Grainger, N. (2001) Herbal Drugs and Phytopharmaceuticals. 2th Edition, Medpharm Scientific Publishers, Stuttgart, 237-239.

[33] Bone, M.E., Wilkinson, D.J. and Young, J. (1990) Ginger Root-A New Antiemetic. The Effect of Ginger Root on Postoperative Nausea and Vomiting after Major Gynaecological Surgery. Anaesthesia, 45, 669-671. http://dx.doi.org/10.1111/j.1365-2044.1990.tb14395.x

[34] Visalyputra, S. and Petchpaisit, N. (1998) The Efficacy of Ginger Root in the Prevention of Postoperative Nausea and Vomiting after Outpatient Gynaecological Laparoscopy. Journal of Anesthesia, 53, 486-510.

[35] Arfeen, Z., Owen, H. and Plummer, J.L. (1995) A Double-Blind Randomized Controlled Trial of Ginger for the Prevention of Post Operative Nausea and Vomiting. Anaesthesia and Intensive Care Journal, 23, 449-452.

[36] Eberhart, L.H. and Oliver, R.M. (2003) Ginger Dose Not Prevent Post Operative Nausea and Vomiting after Laparoscopic Surgery. Anesthesia and Analgesia, 96, 995-998. 